\title{
HISTÓRIAS ALÉM DAS JANELAS
}

\section{STORIES BEYOND THE WINDOWS}

\author{
Gislene da Silva Oliveira ${ }^{1}$ \\ Joana d'Arc Vasconcelos Neves ${ }^{2}$
}

Tenho pelo menos 200 vizinhos e não conhecia nenhum. Em dez anos, não sei suas origens, seus nomes, seus ofícios, suas histórias. Sobre eles, não aprendi absolutamente nada! A vida para além da abertura retangular na parede externa, com função única de trazer iluminação e ventilar meu apartamento, sempre foi um mistério, que eu, por pressa, falta de interesse, ou, simplesmente, nenhum motivo aparente, encobri com escuras cortinas e nunca procurei desvendar.

Então, de repente, um enigmático vírus descortinou-se, como um misterioso evento crítico no mundo contemporâneo. Sua forma de contágio e o curso rápido para desenvolver a doença impuseram a necessidade de isolamento.

Sintomas como tosse, febre e dificuldade para respirar já não indicam mais meras "viroses", como genericamente se costumavam tratar. Ao contrário, trazem à tona realidades encobertas tal qual a parte encoberta de um iceberg. São diferenças sociais gritantes, sistemas de saúde deficitários iminentes ao colapso, interesses políticos e econômicos que se sobrepõem a vidas. Trazem a crise, o caos.

Agora são sintomas de preocupação, pânico, dor e, subitamente, alteridade. Como um enigma, por uma razão diminuta, desprovida de metabolismo independente, abriram-se janelas para um mundo além das cortinas escuras, revelando não apenas o tempo presente, mas um passado desumanizado que se desnuda diante do novo que busca os traços de humanidades:

- Bom dia! Como está? O dia está ensolarado, não é?

- Bom dia! Verdade. Resolvi aproveitar para repor um pouco de vitamina D!

Aos poucos são duas, três, quatro, muitas janelas abertas... Da minha, espreito a vizinhança. Sim, a mesma que por longos anos evitei conhecer. Descubro que o moço da frente já mora há 8 anos neste prédio. Nunca nos falamos.

Disfarçadamente observo o casal que mora à direita, tem seus três filhos. Da janela do meu apartamento, reconheço a vida adolescente, ouço suas vozes e músicas cantaroladas à altura de quem usa fones de ouvido, sem nenhuma intenção de ouvir do mundo nada além das canções dos seus ídolos musicais.

Nunca antes alguns metros quadrados foram tão agradáveis e significativos à vida dos apartamentos. Nossas pequenas sacadas, em tempo de pandemia, transformaram-se em imensos palcos que comportam os traços da humanidade, a grandeza dos gestos e a boniteza da solidariedade. Dela, contemplo cumprimentos amáveis, cantorias, preocupações sinceras, sorrisos e olhares ternos que roçam outros olhares e substituem a ausência do toque, já tão ausente antes da presença de um vírus anunciado. Ao espiar, vejo que a quarentena, definida pela reclusão do indivíduo, paradoxalmente possibilitou um movimento de aproximação. Passamos a cumprimentar nominalmente os vizinhos que não conhecíamos. Estranhamos, sentimos mesmo até falta, se no horário, implicitamente marcado, o aceno lento do senhorzinho do prédio ao lado nos falta. Ele é do grupo de risco e uma preocupação súbita nos

\footnotetext{
${ }^{1}$ Mestra em Linguagens e Saberes na Amazônia (PPLSA/UFPA). E-mail 100gisoliveira@gmail.com.

2 Doutora em Educação. Docente do Campus de Bragança (FACED/UFPA), Coordenadora do Curso de Especialização de Jovens e Adultos para Juventude (UFPA). Docente do Programa de Pós-Graduação em Linguagens e Saberes na Amazônia (PPSA/ UFPA). E-mail: jdneves@ufpa.br.
} 
invade, tememos pelo tão ilustre desconhecido. Pensamos o pior... Um pouco atrasado, lá vem ele no compasso lento do seu tempo, aliviando nossa sensação de mal-estar. Atrasado?!? Para quê? Para quem? Temos tempo e os tempos são outros.

Entreabertas, as janelas nos permitem ver a aproximação familiar. Há quanto tempo não falávamos com parentes ou amigos? São primos, tios, avós. Meus Deus! Quanta gente querida, de cuja existência sequer lembrávamos ou se lembrávamos era num espaço tão breve de tempo que não tardava voltar ao esquecimento.

Esquecimento? Quem em sã consciência se esquece de visitar, procurar, ligar para seus próprios pais? Ah, lembrei! Nós, seres ditos humanos que desumanizados em nossas carreiras, na vida acadêmica, nas obrigações sociais trilhamos por caminhos retos e asfálticos, e não nos permitimos entrecortar por vielas, atalhos, veredas de sentimentos que se perderam ou deixaram aguardar empoeirados num canto da vida racional e prática.

Não, não entramos em isolamento social! Há tempos estamos isolados. Mas agora, no abrir das janelas, de repente nos aproximamos do mundo! A China nunca foi tão perto! Mesmo nas breves piadas: Nem aqui, nem na China. Pelo menos, virtualmente mais perto. São novos tempos e nada será como antes, tudo mudou, as normalidades são outras e nós estamos mudando. Estamos mais antenados, buscamos aplicativos para a realização de vídeos chamadas, reuniões, conferências, videoaulas. Certa vez, ouvi de um amigo que as reuniões de trabalho deveriam ser feitas em pé para que não demorassem tanto. Hoje, ironicamente, que falta elas nos fazem. Baixamos aplicativos para vermos pessoas que sequer ouvíamos as vozes, era deselegante enviar áudios longos e, em geral, no WhatsApp o recado era claro: SÓ CHAMADAS URGENTES. Hoje temos urgência em chamar, ver e ouvir através de pequenas janelas virtuais abertas em celulares ou computadores.

De janelas e sacadas, aprendemos e ensinamos novas lições, batemos e ouvimos panelas que tocam, sempre à mesma hora, uma amarga sinfonia. E da luz que agora atravessa a janela, outrora tão escura, buscamos outras formas de caminhar. Felizmente, passamos a ver e sentir o calor dos aplausos para aqueles que passaram a ser reconhecidos como os nossos heróis sem capa, sem superpoderes, sem filmes da DC ou da Marvel, sem nomes estampados em jornais e revistas, mas escritos na incrível narrativa: A HUMANIDADE contra COVID19, cujos capítulos contam as muitas histórias vividas além das nossas janelas. Tenho pelo menos 200 vizinhos, conheço alguns. Da abertura de minha janela, contemplo-os. Quisera eu poder abraçá-los. 


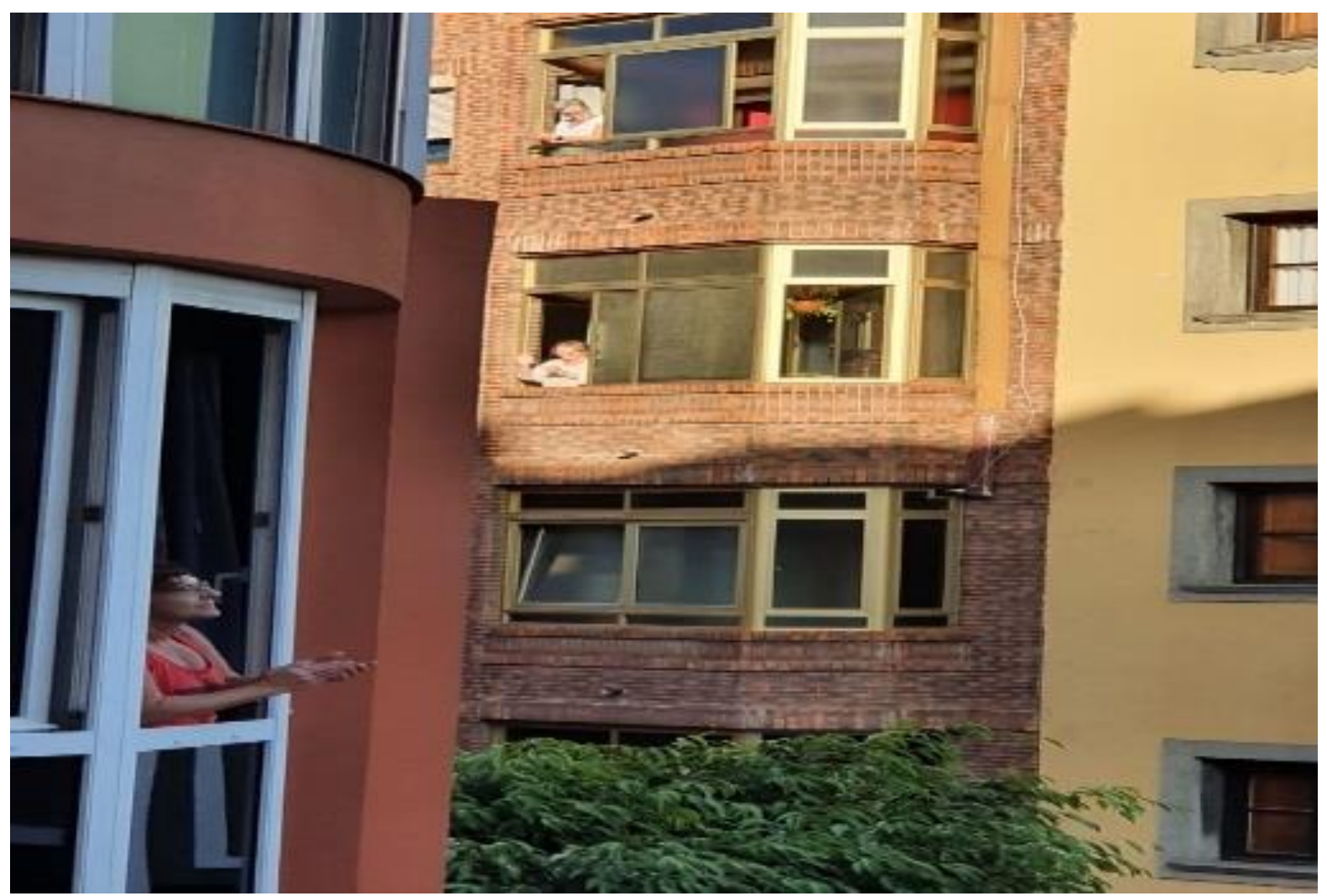

Fonte: Acervo pessoal.

Data de submissão: 05.08 .2020

Data de aprovação: 27.10 .2020 